\title{
Comparison of Thermal Stability of Dry High- strength Concrete and Wet High-strength Concrete
}

\author{
Tatiana Musorina ${ }^{l}$, Aleksandr Katcay ${ }^{l,}{ }^{*}$, Anna Selezneva ${ }^{l}$ and Victor Kamskov ${ }^{2}$ \\ ${ }^{1}$ Peter the Great St. Petersburg Polytechnic University, 29 Politechnicheskaya St., St. Petersburg, \\ 195251, Russia \\ ${ }^{2}$ Moscow State University of Civil Engineering; 26, Yaroslavskoe sh., Moscow, 129337, Russia
}

\begin{abstract}
High-strength concrete is a modern material, which occupies it's own niche on the construction material market. It is applicable in a largescale high-rise construction, particularly an underground construction is a frequently used solution for a space saving. Usually underground structure is related to a wet usage environment. Though not all properties of the highstrength concrete are investigated to the full extent. Under adverse climatic conditions of the Russian Federation one of the most important properties for constructional materials is a thermal capacity. Therefore, the main purpose of the paper is to compare a thermal capacity of the high-strength concrete in humid conditions and a thermal capacity of the high-strength concrete in dry operational condition. During the study dependency between thermal capacity and design wall thickness and ambient humidity has to be proven with two experiments. As a result the theoretical relation between thermal capacity characteristic - thermal inertia and wall thickness and ambient humidity was confirmed by the experimental data. The thermal capacity of a building is in direct ratio to the construction thickness. It follows from the experiments and calculations that wet high-strength concrete has less thermal stability.
\end{abstract}

\section{Introduction}

Nowadays the construction of a high-rise constructions is highly developed. From this perspective the industry requires high-strength materials, in particular concrete. Highstrength concrete is a modern material, which occupies unique niche on the world construction market.

High-strength concrete of classes over B60 is made of a Portland cement based binder [1]. High-strength concrete during hardening cures much quicker than common concrete. This is related to the low water-cement ratio, which is achieved through the use of a plasticizer and high heat of setting due to quick humidification and high level of a binder content [2].

Since most of Russian cities are located in a climate with low temperature scenario, it is important to consider to what extent a material used in the construction possesses characteristics necessary for comfortable indoor climate, such as: thermogravitational

\footnotetext{
* Corresponding author: zenit67ru@mail.ru
} 
convection[3], energy efficiency[4-9], thermal stability. High-strength concrete has to be strength, frost resistance and water penetration resistance tested [10,11], however under Russian harsh climatic conditions thermal capacity is an extremely important characteristic of a building envelope. The accumulative capacity of wall structures determines the amount of heat absorbed and passed by the structure and used to maintain a required temperature level of the room and enclosing wall when the temperature of the external heat source changes [12]. According to [13], thermal stability is one of the most important topics in the building design, as it measures how quickly a material gains or loses heat to the environment. The thermal stability is property of the thermal conductivity coefficient, density of the material, specific heat and heat transfer resistance [14]. Consequently a thermal stability calculation may be summarized as estimation of an internal surface temperature swing or as measurement of damping of temperature oscillations in building structures. [15]. In superstructure building construction with underground and semi-basement floors, basements it is important to consider moisture-holding capacities of rooms with building structures and external environment.

The method of thermal stability estimation for building structures is based on determination of a range of temperature on internal surface of a building structure [16]. Stationary method based on the regularities of stationary thermal stability, as shown by theoretical and experimental studies, provides greater accuracy [17]. The application of heatresistant materials reduces energy consumption of heating or wall thickness. According to [18] the thermal capacity characteristic is a thermal lag D

$$
\begin{gathered}
D=R \cdot s \\
R=\frac{\delta}{\lambda} \\
D=\frac{\delta}{\lambda} \cdot s=\frac{s}{\lambda} \cdot \delta
\end{gathered}
$$

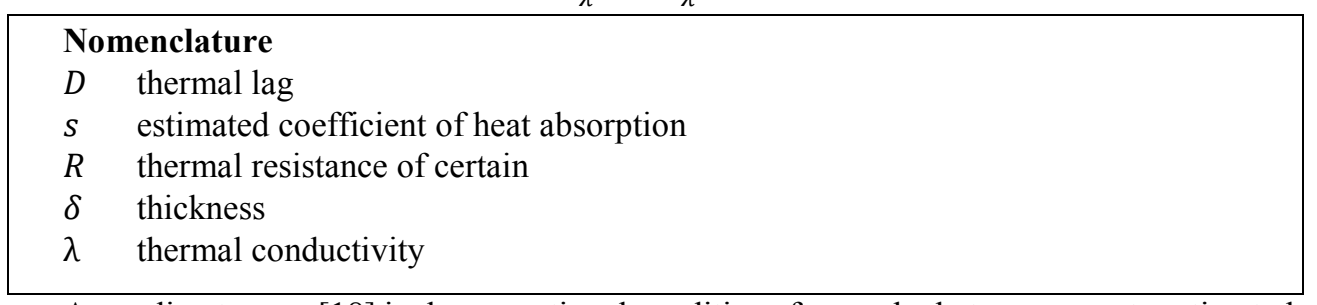

According to app. [18] in dry operational conditions for crushed-stone concrete estimated coefficient of heat absorption is 16.77 , thermal conductivity is 1.74 , for wet operational conditions 17.88 and 1.86 subsequently.

Then in dry operational conditions:

In wet operational conditions:

$$
\frac{s}{\lambda}=\frac{16.77}{1.74}=9.64
$$

$$
\frac{s}{\lambda}=\frac{17.88}{1.86}=9.61
$$

Hence with equal thickness of structure the thermal lag D in wet operational conditions is less than it is in dry operational conditions.

The thermal stability of construction depends on the following factors [19]:

1) physical condition and structure, which are determined by the phase state of matter;

2) a degree of crystallization and size of crystals;

3) anisotropy of the thermal conductivity of crystals and the direction of heat flow;

4) a volume of porosity of the material and the characteristics of the porous structure;

5) chemical composition and presence of impurities (the latter especially affects the conductivity of crystalline bodies);

6 ) maintenance conditions, depending on temperature, pressure, humidity of the material; 
7) thickness of the structure;

8) sequence of layers.

Dry air enclosed in small closed pores, which is practically not possible convective heat transfer, has the minimum conductivity. In this case, the thermal conductivity of air is minimal and counts $0.023 \mathrm{~W} /\left(\mathrm{m} \cdot{ }^{\circ} \mathrm{C}\right)$. Therefore, the increase in porosity of the material is the main way to reduce thermal conductivity.

The thermal conductivity of the materials increases significantly with hydration. This is because the moisture that falls into the pores and partly replaces the air and increases the thermal conductivity of the material, because the thermal conductivity of water $\lambda=0.58$ $\mathrm{W} /\left(\mathrm{m} \cdot{ }^{\circ} \mathrm{C}\right)$ greater in 25 times than the thermal conductivity of air. Thermal lag is in inverse ratio to thermal conductivity, hence with thermal conductivity decrease thermal stability increases. Estimated coefficient of heat absorption depends on material and humidity under operating conditions. Whereas thermal lag is in inverse ratio to estimated coefficient of heat absorption, which is bigger in the wet operational conditions than in normal or dry ones.

Nevertheless, there are a few articles on the issue of a thermal stability of a high-strength concrete. Because of this, the purpose of this article is to discover the characteristics of thermal stability for high-strength concrete.

\subsection{Goal}

From the foregoing it follows that in order to reasonably conclude about the thermal features of wet high-strength heavy concrete, it is necessary to examine it and see how its thermal features differ from the properties of a dry high-strength heavy concrete and from which it depends.

\subsection{Tasks}

To achieve the objectives of the article it is required:

- to compare the thermal stability of the structure depending on its thickness;

- to carry out experiments to study the thermophysical features of materials;

- to compare properties of wet high-strength heavy concrete and dry high-strength heavy concrete;

- graphically see the difference between the characteristics of wet high-strength heavy concrete and dry high-strength heavy concrete.

\section{Materials and Methods}

\subsection{Materials}

For the experiment there were made 2 samples of wet high-strength heavy concrete and 1 sample of dry high-strength heavy concrete with the following composition:

Table 1. Composition of concrete.

\begin{tabular}{|c|c|c|c|c|c|c|c|c|c|c|c|}
\hline \multirow[b]{2}{*}{ № } & \multirow[b]{2}{*}{ Concrete } & \multirow[b]{2}{*}{$\begin{array}{c}\text { Cement, } \\
{[\mathrm{kg}]}\end{array}$} & \multirow[b]{2}{*}{$\begin{array}{l}\text { Slag, } \\
{[\mathrm{kg}]}\end{array}$} & \multirow[b]{2}{*}{$\begin{array}{c}\text { Sand, } \\
{[\mathrm{kg}]}\end{array}$} & \multicolumn{2}{|c|}{$\begin{array}{c}\text { Crushed } \\
\text { stone, }[\mathrm{kg}]\end{array}$} & \multirow[b]{2}{*}{$\begin{array}{c}\text { Water, } \\
{[\mathrm{kg}]}\end{array}$} & \multirow{2}{*}{$\begin{array}{c}\text { Water- } \\
\text { cement } \\
\text { ratio }\end{array}$} & \multirow{2}{*}{$\begin{array}{c}\text { Plasticizer } \\
\text { PF } 3196 \\
0,5 \%,[\mathrm{~kg}]\end{array}$} & \multirow[b]{2}{*}{$\begin{array}{l}\text { Density, } \\
{\left[\mathrm{kg} / \mathrm{m}^{3}\right]}\end{array}$} & \multirow[b]{2}{*}{$\begin{array}{l}\text { Strength, } \\
{[\mathrm{MPa}]}\end{array}$} \\
\hline & & & & & $\begin{array}{l}5-10 \\
\mathrm{~mm}, \\
{[\mathrm{~kg}]}\end{array}$ & $\begin{array}{c}10-20 \\
\mathrm{~mm}, \\
{[\mathrm{~kg}]}\end{array}$ & & & & & \\
\hline 1 & $\begin{array}{l}\text { high- } \\
\text { strength } \\
\text { heavy } \\
\text { concrete }\end{array}$ & 380 & 76 & 798.4 & 273 & 728.5 & 175 & $\begin{array}{c}0.38 \\
(0.47)\end{array}$ & 1.90 & 2428 & 70.1 \\
\hline
\end{tabular}




\subsection{Methods}

The experiment consists on simulating the real conditions of typical structures in cold climates, it is by drastic temperature changes in few hours during the same day. It has built a box (imitation of a closed room) for dry high-strength concrete simulating the indoor conditions. It consists of the following: a wooden board, a heat insulator, a concrete sample. It is represented in fig. 1. Also it has built a 2 cubes for wet high-strength concrete. It consist of the following: a heat insulator, a concrete sample. It is represented in fig. 2.

Installing the appropriate sensors and equipment inside it is the way to be in accordance with real characteristics of buildings [20-24]. The initial temperature of the air inside the chamber was $18^{\circ} \mathrm{C}$, internal environment. The initial temperature of the air inside the chamber is $30^{\circ} \mathrm{C}$, followed by a drastic drop down to $0^{\circ} \mathrm{C}$ and then up to the initial temperature. The temperature was measured with the help of 3 sensors: on the outer surface, inside the model in the middle, inside the model at the edge. In this way it is able to assess the behavior which really apply in real life conditions for giving future conclusions about the material. As explained before and in accordance to the aim of this paper, the idea is to simulate with all possible details all conditions of environments in similar climatic conditions tendencies.

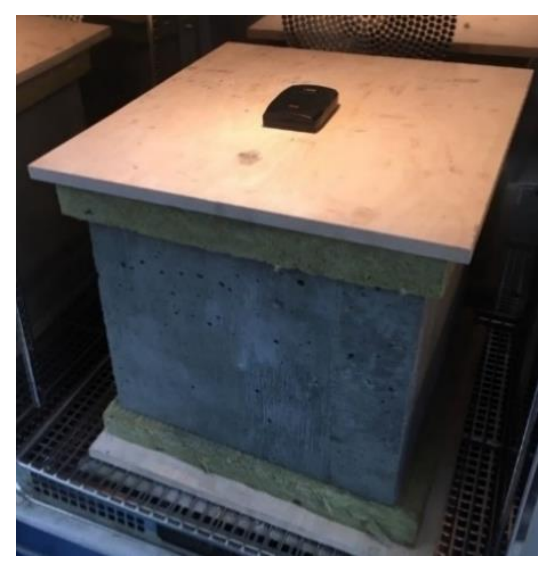

Fig. 1. Dry high-strength concrete.

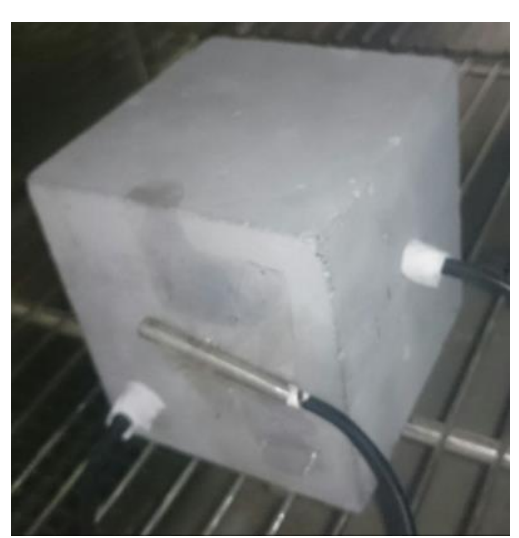

Fig. 2. Wet high-strength concrete.

The sample was placed in a chamber (initial temperature inside the structure was approximately $30^{\circ} \mathrm{C}$ ). The sample was at $30^{\circ} \mathrm{C}$ degrees for 60 minutes. Then followed an decrease of temperature in the chamber to $0^{\circ} \mathrm{C}$ degrees. The sample was heated until the sensor inside the structure began to register an increase in temperature. Due to the fact that the material is thermally stable, it continues to cool down, even if the chamber has at plus temperature. Then the material was cooled until the temperature of the sensor began to fall.

\section{Results}

The results of the experiment are shown at fig. 3 where presented changes in temperature of wet high-strength concrete that are depended on temperature in samples through time. 


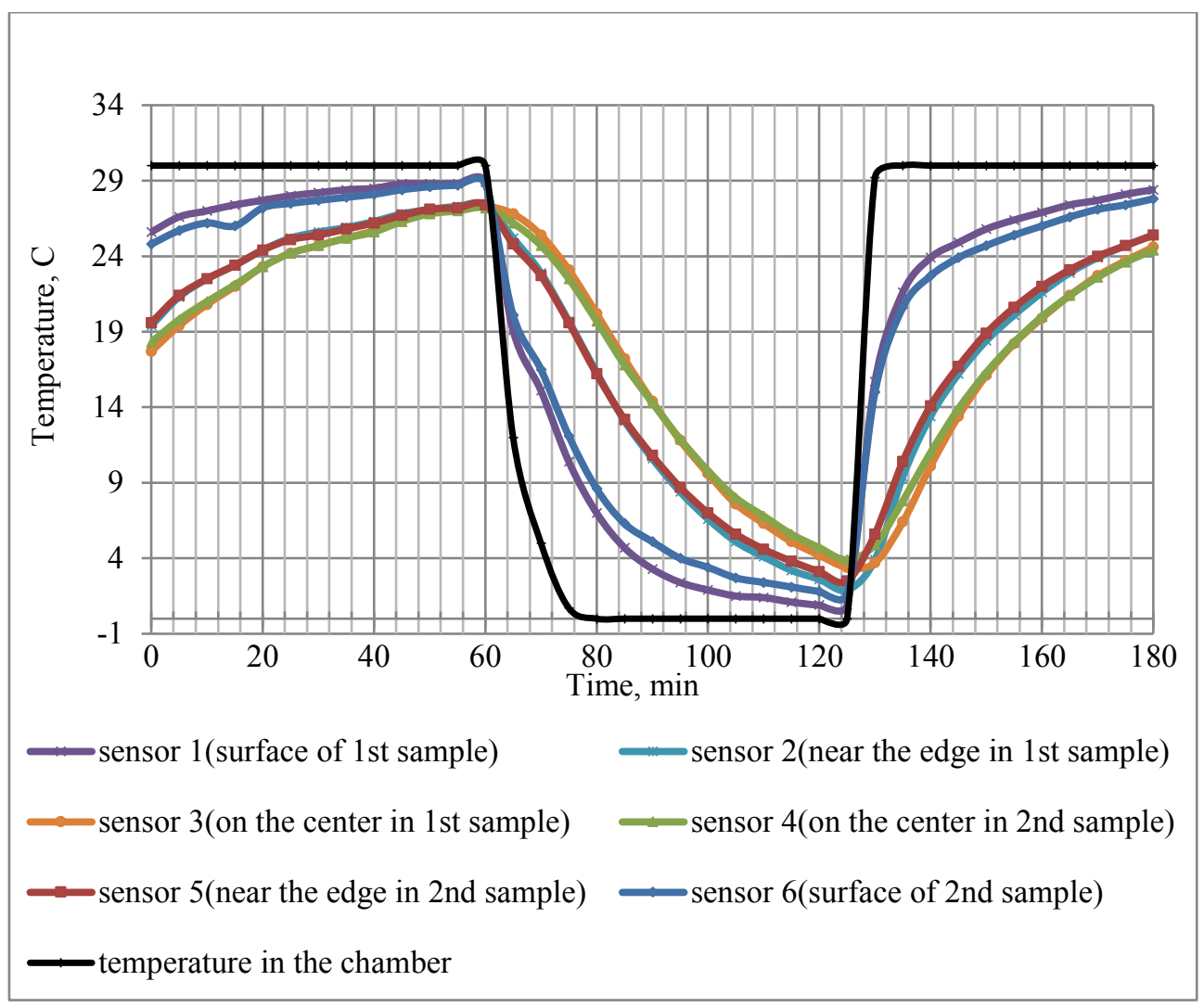

Fig. 3. Graph of temperature of concrete change from temperature through time.

The dependence of a temperature lag from material thickness is confirmed by the diagram Fig.3: sensors 2, 5, located close to the edges of models, shows more abrupt change of temperature during a switch of a heat regime inside the chamber than sensors 3,4 , located inside the models in the middle. Hence with increase of material thickness the thermal stability of a building construction increases. 


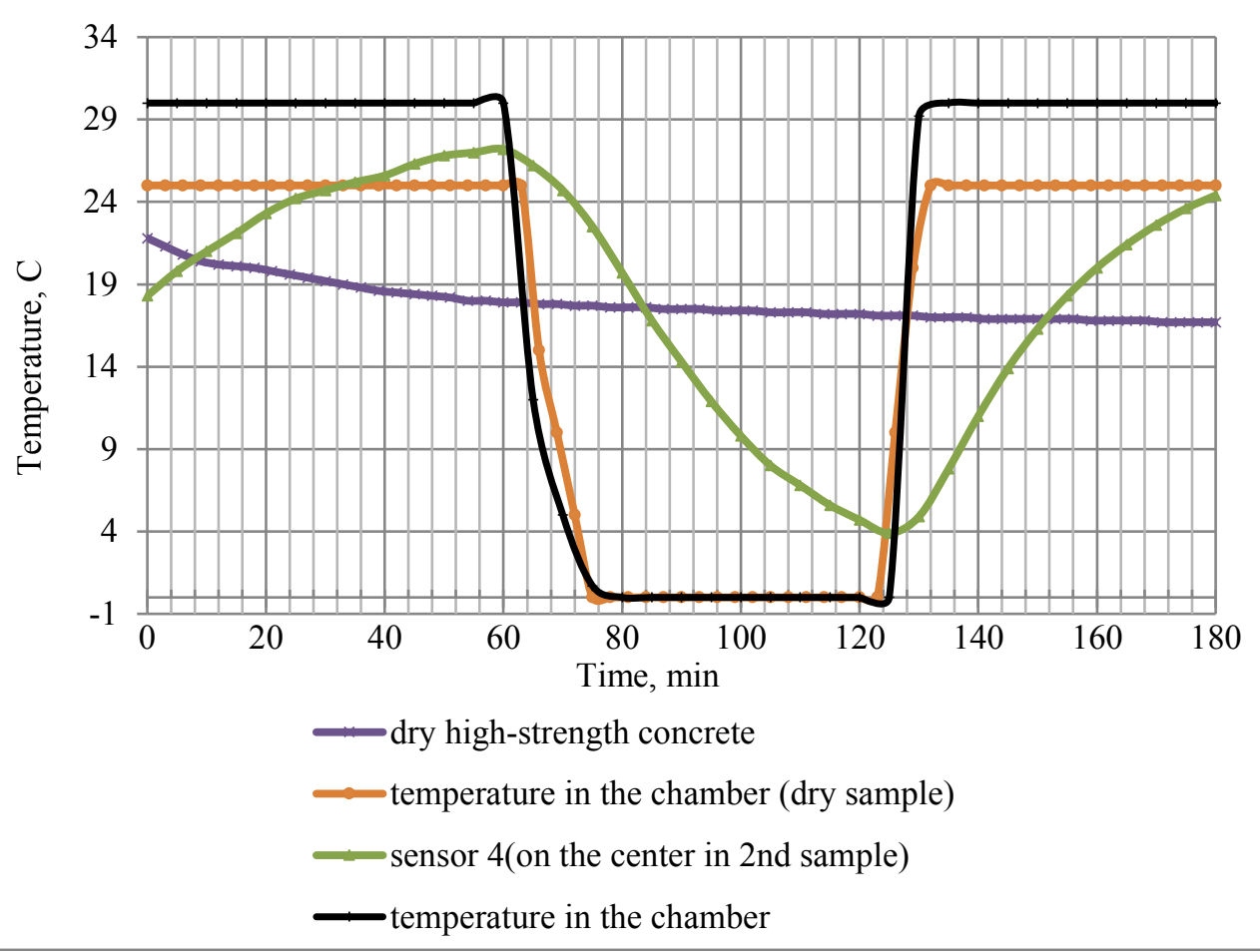

Fig. 4. Graph of temperature of wet and dry concretes change from temperature in chamber through time.

At fig. 4 it can be seen that in wet high-strength concrete the temperature swing is significantly more than one in dry high-strength concrete. That confirms accuracy of the above theoretical comparison of thermal stability of concrete under wet and dry conditions.

\section{Discussion}

In underground construction it should be considered, that thermal stability of wet highstrength concrete is less than thermal stability of dry high-strength concrete, since alternatively thermal properties of the basement areas will differ considerably from thermal properties of the building superstructure.

For more accurate research of thermal properties of high-strength concrete for usage in underground construction a frost resistance experiment should be conducted.

\section{Conclusions}

1. It was experimentally proved, that thermal capacity of a building is in direct ratio to the construction thickness;

2. It follows from the experiments and calculations that wet high-strength concrete has less thermal stability;

\section{Acknowledgement}

Thanks to the laboratories of Institute of civil engineering from Peter the Great St. Petersburg Polytechnic University which provided all equipment and materials and helped to do experiments. 


\section{References}

1. O. M. Smirnova Mag. of Civil Eng. 6, 12-22 (2016).

2. M. M. Batdalov, H. N. Maiev, D. K. S. Batayev, S. G. K. Bata Safety of struct. 1, 4547 (2013).

3. N. Vatin, M. Petrichenko, D. Nemova: Applied Mech. and Mat. 633-634, pp. 10071012 (2014).

4. N. Vatin, O. Gamayunova.: Advanced Mat. Research. 1065-1069, pp. 2159-2162 (2015).

5. V. Kostenko, N. Gafiyatullina, A. Semchuk, M. Kukolev: Mag. of Civil Eng. 68, No 8, pp. 18-25 (2016).

6. D. D. Zaborova, T. A. Musorina, M. R. Petrichenko St. P. State Polytechnical U. Journal 231,18-26 (2017).

7. D. Zaborova, M. Petrochenko, L. Chernenkaya MATEC Web of Conferences 73, 27 (2016).

8. S. Korniyenko Procedia Eng. 117, 191-196 (2015).

9. M. Petrichenko, N. Vatin, D. Nemova, N. Kharkov, A. Staritcyna Applied Mech. and Mat. 627, 297-303 (2014).

10. State Standart 31914 High-strength heavy-weight and fine-grane concretes for situcasting struct. Rules for control and quality assessment (2012).

11. EN 1992 Eurocode 2. Design of concrete structures (1992).

12. D. Zaborova, T. Musorina, A. Selezneva, A. Butyrin, Therm. Resist. and accum. of Heat by the Wall Constr. (International Scientific Conference Energy Management of Municipal Transportation Facilities and Transport EMMFT), 473 (2017).

13. D. D. Zaborova, T.A. Musorina, M.R. Petrichenko: St. P. State Polytechnical U. Journal 23. 1, 18-26 (2017).

14. Y.G. Barabanshikov, S.V. Belyaeva, M. Antonova, S.V. Vasyutina: Procedia Eng., 4149 (2015).

15. The Ministry of construction of Ukraine DBN V.2.6. Thermal insulation of buildings, $64-65(2006)$.

16. State Standart 26253 Buildings and struct. Method for determining the building struct ability to maintain (1984).

17. M. Y. Leshchinsky, Testing of concrete: Right allowance (1980).

18. SP 50.13330 Thermal protection of buildings (2012).

19. Y. P. Gorlov and etc. The techn. of thermal insulation mat. (1980).

20. A. Keyvanfar, A. Shafaghat, M. Zaimi A. Majid, B. L. Hasanuddin, M. W. Hussin, Kherun Nita Binti Ali, A. D. Saad Journal of Renewable \& Sustainable Energy Reviews 39, 277-293 (2014).

21. B. Nagy, S. G. Nehme, D. Szagri, Energy Procedia 78, 2742 - 2747 (2015).

22. V.Borovkov, A. Kalyutik, V. Sergeev, Heat and mass transfer equipment. Publishing house of Polytechnic University, 231 (2008)

23. V. Pukhkal, V. Murgul, IOP Conference Series: Earth and Environmental Science, 90, 012211 (2017) DOi - 10.1088/1755-1315/90/1/012211

24. N. Harmathy, J. Kontra, V. Murgul, Z. Magyar, Advances in Intelligent Systems and Computing, 692, 563 - 576 (2018) DOi- 10.1007/978-3-319-70987-1_60 